\title{
INOVASI YOUNG COMMUNITY BASED-INITIATIVES DALAM PARIWISATA SURABAYA (RASA MEMILIKI, INOVASI DAN KETERLIBATAN PEMUDA DALAM TURUT MENGEMBANGKAN PARIWISATA SURABAYA)
}

\author{
Nur Emma Suriani* \\ emma.suriani23@gmail.com
}

\begin{abstract}
The aim of this research is to analyse the knowledge of young generations (teenagers) to Surabaya's tourism. Also, this research investigates how deep their sense of belongings and innovations in developing Surabaya's tourism. This relates to young people's understanding about destinations in Surabaya, location, accessibility, as well as history around them. This research examines participation of young generations to tourism development in Surabaya, astourism often ignores the participation of local community. Tourism often only asks the local people to be the spectator. The positive benefits of tourism are often enjoyed by people outside Surabaya. Therefore, this research focuses on the knowledge of local people, particularly the teenagers.
\end{abstract}

Keywords: Tourism in Surabaya, young generation, sense of belonging, innovation.

\section{Pendahuluan}

Perkembangan pariwisata di provinsi Jawa Timur memberikan imbas pada kepariwisataan di Surabaya. Pariwisata Surabaya menunjukkan pertumbuhan yang cukup menggembirakan. Hal ini ditunjukkan dengan jumlah wisatawan internasional yang datang ke Surabaya selama tiga tahun antara tahun 2011dan 2013 adalah 279.230, 323.087, dan 350.017 jiwa (Badan Pusat Statistik Kota Surabaya 2014). Pertumbuhan ini membuat capaian realisasi kunjungan wisatawan jauh di atas target dengan rata- rata di atas $150 \%$ pada 2011-2013 (Badan Pusat Statistik Kota Surabaya 2014). Demikian pula dengan wisatawan domestik. Pada kurun waktu 2011-2013 tercatat lebih dari 9 juta orang mengunjungi Surabaya, dan bahkan angka tersebut mencapai 11 juta jiwa pada tahun 2013 (Badan Pusat Statistik Kota Surabaya 2014).

Beberapa sarjana berpendapat bahwa pariwisata memiliki potensi untuk menjadi sarana untuk meningkatkan perekonomian daerah, khususnya melalui kemampuannya untuk menciptakan lapangan kerja, pen-

* Dosen Program Studi D3 Pariwisata, Fakultas Vokasi, Universitas Airlangga, Surabaya. 
dapatan ekspor dan pendapatan bagi pemerintah dan individu (Cornelissen 2005; Sharma, Dyer, Carter \& Gursoy 2008). Namun hal itu tentu saja harus diimbangi dengan dukungan yang kuat dari masyarakat lokalnya.

\section{Surabaya sebagai Daerah Tujuan Wisata}

Surabaya memiliki luas sekitar 333,063 kilometer persegi, dengan jumlah penduduk 2.813.847 jiwa menurutsensus 2010 (Statistik Jawa Timur). Kota Surabaya merupakan ibukota Provinsi Jawa Timur dan merupakan kota terbesar kedua di Indonesia setelah Jakarta. Daerah metropolitan Surabaya yaitu Gerbangkertosusila yang berpenduduk sekitar 10 juta jiwa, adalah metropolitan terbesar kedua di Indonesia setelah Jabodetabek. Surabaya dilayani oleh Bandar Udara Internasional Juanda, Pelabuhan Tanjung Perak, dan Pelabuhan Ujung. Posisi tersebut membuat kota Surabaya menjadi pusat perdagangan dan jasa di kawasan Indonesia Timur.

Visi dan misi kota Surabaya adalah bahwa pada tahun 2025 kota Surabaya ditargetkan menjadi kota perdagangan dan jasa, yang mampu memajukan semua aspek pembangunan kota yang didorong oleh kemandirian ekonomi berdaya saing nasional dan internasional yang memiliki karakter lokal. Pemahaman makna karakter lokal ini mencakup aspek yang sangat luas baik dalam aspek ekonomi, sosial-budaya maupun dalam aspek lingkungan fisiknya.

Sebagai kota terbesar nomor dua di Indonesia, Surabaya memang bukan hanya menjadi pusat pertumbuhan kawasan Indonesia timur dan pusat perdagangan yang dinamis, tetapi sekaligus juga potensial dikembangkan menjadi salah satu daerah tujuan wisata yang banyak dikunjungi wisatawan, baik untuk kepentingan bisnis maupun liburan.

Tidak sedikit fasilitas rekreasi, kekayaan budaya, dan peninggalan sejarah yang bisa dikemas dan dijadikan daya tarik sektor pariwisata. Dari segi gastronomi, Surabaya boleh dikata adalah gudangnya makanan khas daerah, seperti semanggi Suroboyo, lontong balap Wonokromo, atau jajan pasar Blauran yang khas dengan getuk lindrinya, dan masih banyak lagi. Dari segi fasilitas atau infrastruktur, kota Surabaya juga memiliki banyak hotel berbintang mulai dari hotel bintang tiga hingga bintang lima. Belum lagi pusat perbelanjaan seperti Tunjungan Plaza, Galaxy Mall, Surabaya Plaza, Royal Plaza, Pakuwon Mall, Grand City hingga City of Tomorrow dan pusat-pusat hiburan merupakan modal dasar bagi kota ini untuk mengembangkan sektor pariwisata.

Saat ini beberapa obyek dan daya tarik wisata unggulan yang dimiliki kota Surabaya, antara lain Kebun Binatang, Pantai Ria dan THP Kenjeran, Taman Hiburan Rakyat, Museum Mpu Tantular, Monumen Kapal Selam (Monkasel) , Taman prestasi dengan wisata air Kali Mas, Tugu Pahlawan, Kawasan Masjid Ampel yang baru saja direhabilitasi besar-besaran, Taman Remaja, Pusat Grosir Surabaya (PGS) dulu Pasar Turi, Pusat jajan Kya-kya Kembang Jepun serta icon baru kota Surabaya jembatan Suramadu, dan berbagai potensi wisata lain yang belum terpoles dengan baik.

Salah satu masalah pariwisata yang dialami oleh Surabaya adalah rendahnya pengetahuan dan partisipasi masyarakat pada obyek wisata yang ada di Surabaya. Hal ini tidak hanya dialami oleh mereka yang berada di luar Surabaya, namun juga mereka yang merupakan penduduk lokal Surabaya terutama remaja. Pemuda atau remaja mempunyai peran yang sangat penting dalam pembangunan, termasuk pengembangan pariwisata. Oleh karena itu. dalam pengembangan pariwisata partisipasi masyarakat khususnya para remaja sangat diharapkan. Hal ini senada seperti yang diungkapkan oleh Cole bahwa partisipasi masyarakat dalam proses pembangunan pariwisata telah diakui secara luas sebagai 
sesuatu yang penting (Cole 2008; Grybovych, Hafermann \& Mazzoni 2011; Lamberti, Noci, Guo \& Zhu 2011). Hal ini diyakini bahwa partisipasi penduduk setempat dalam hasil perencanaan pariwisata dukungan yang lebih baik dan sikap terhadap pariwisata dan selanjutnya. Hal ini menciptakan sebuah industri yang sukses (Grybovych et al 2011; Timothy 2002), Namun apabila partisipasi masyarakat terutama remaja terhadap pariwisata kurang, akibatnya dukungan dan kepedulian masyarakat local pun menjadi jauh dari harapan. Rasa memiliki dan cinta pariwisata Surabaya yang selama ini dicitacitakan hanya akan menjadi angan-angan.

\section{Pengetahuan Remaja tentang Obyek Wisata di Surabaya}

Untuk mengetahui bagaimana rasa memiliki, inovasi, dan keterlibatan remaja dalam pariwisata, khususnya pariwisata di Surabaya maka penelitian ini menggunakan responden remaja yang berusia 17-25 tahun. Hasil dari wawancara terhadap 20 orang responden yang mayoritas remaja diketahui bahwa pengetahuan remaja terhadap keberadaan obyek-obyek wisata yang ada di Surabaya sangat baik, karena mayoritas responden dapat menyebutkan lima obyek wisata yang selalu ramai dikunjungi di Surabaya, seperti: Kebun Binatang Surabaya, Monumen Kapal Selam, Taman Remaja Surabaya, Tugu Pahlawan, dan Pantai Ria Kenjeran. Selain lima obyek wisata di atas beberapa responden juga menyebutkan obyek wisata lain yang pernah mereka kunjungi seperti wisata mangrove, House of Sampoerna, dan Taman Bungkul.

Pengetahuan responden terhadap obyek-obyek wisata di Surabaya masih sebatas nama dan lokasi dari obyek wisata saja. Sedangkan untuk pengetahuan yang berkaitan dengan harga tiket masuk serta atraksi yang dapat dinikmati, rata-rata responden tidak tahu secara pasti. Hal ini dimungkinkan karena rata-rata kunjungan responden ke obyek-obyek wisata yang hanya sekali dan jarak kunjungan responden ke sebuah obyek wisata yang terlalu panjang. Sehingga tidak mengetahui ada perubahan harga terhadap tiket masuk ke sebuah obyek wisata. Dua puluh orang responden remaja yang diwawancarai tentang obyek wisata yang ada di Surabaya juga selalu menyebut Kebun Binatang Surabaya (KBS) sebagai obyek wisata yang mereka kunjungi. Hal ini menunjukkan bahwa Kebun Binatang Surabaya sebagai icon kota Surabaya merupakan salah satu obyek wisata yang paling populer dan menjadi tujuan utama dari masyarakat sebelum mengunjungi obyek wisata yang lain.

Berkaitan dengan pengetahuan tentang kebijakan Pemerintah Kota Surabaya terkait pariwisata, mayoritas responden menjawab sama sekali tidak tahu, bagaimana kebijakan Pemerintah Kota berkaitan dengan pariwisata. Hal ini menunjukkan bahwa Pemerintah Kota Surabaya perlu lebih mensosialisaikan kebijakan-kebijakan mereka terutama berkaitan dengan kepariwisataan melalui berbagai kegiatan yang melibatkan masyarakat umumnya dan remaja khususnya, melalui media cetak dan media elektronik. Apabila kebijakan pemerintah kota Surabaya terkait dengan pariwisata diketahui secara luas oleh masyarakat maka masyarakat Surabaya khususnya remaja dapat ikut serta berpartisipasi dalam kepariwisataan di Surabaya.

\section{Keterlibatan Remaja dalam Pengambilan Keputusan}

Mayoritas'responden yang diwawancarai beranggapan bahwa pariwisata di Surabaya harus lebih dibenahi lagi terutama dalam hal kelengkapan fasilitas. Seperti yang diketahui beberapa obyek wisata yang ada di Surabaya belum memiliki tempat parkir yang memadai. Masalah kebersihan juga menjadi perhatian dari para responden, mayoritas responden berpendapat bahwa kebersihan di beberapa obyek wisata yang 
sering mereka kunjungi seperti KBS, Pantai Kenjeran harus lebih ditingkatkan lagi.

Begitu juga dengan masalah keamanan. Karena sistem keamanan yang baik dapat meningkatkan keterlibatan pemuda dalam organisasi yang bergerak di bidang pariwisata. Dari 20 responden yang menjawab tidak terlibat sebanyak 17 orang, satu orang tidak menjawab, dan dua orang menjawab terlibat dalam organisasi kepariwisataan yaitu Forum Komunikasi Pengelola Obyak Wisata Surabaya (FORKOM) dan Paguyuban Sadar Wisata di Kota Malang. Hal ini menunjukkan bahwa keterlibatan remaja dalam pariwisata masih sangat minim. Peran penting remaja dalam pembangunan maupun pengembangan pariwisata Surabaya sangat diperlukan. Keterlibatan remaja dalam pengembangan pariwisata diharapkan dapat melahirkan kreativitas dan inovasi-inovasi baru di bidang pariwisata.

Keterlibatan remaja dalam pengambilan keputusan menyangkut pariwisata juga sangat minim. Dari 20 orang responden, ada 9 orang menjawab tidak pernah terlibat dalam pengambilan keputusan menyangkut pariwisata Surabaya, 9 orang yang lain tidak menjawab, hanya dua orang responden yang menjawab pernah terlibat dalam pengambilan keputusan menyangkut pariwisata melaluikomunitas atau organisasi kepariwisataan yang mereka ikuti.

Hal ini menunjukkan bahwa Pemerintah Kota Surabaya perlu lebih mensosialisasikan kebijakan-kebijakan mereka terutama berkaitan dengan kepariwisataan melalui berbagai kegiatan yang melibatkan masyarakat umumnya dan remaja khususnya, melalui media cetak dan media elektronik. Apabila kebijakan pemerintah kota Surabaya terkait dengan pariwisata diketahui secara luas oleh masyarakat maka masyarakat Surabaya khususnya remaja dapat ikut serta berpartisipasi dalam kepariwisataan di Surabaya.

\section{Manfaat Pariwisata bagi Remaja (Involvement of Locals in The Benefits of Tourism)}

Keterlibatan remaja pada kepariwisataan di kota Surabaya dilakukan melalui beberapa cara, antara lain dengan mengunjungi tempat wisata yang ada di Surabaya. Selain itu, mereka juga menggunakan sosial media seperti BBM, Facebook, dan Instagram. Media sosial digunakan oleh para remaja untuk mempromosikan tempat-tempatwisatayang pernah mereka kunjungi. Biasanya mereka melakukan foto-foto dan selanjutnya mengupload hasil foto tersebut ke media sosial dengan harapan agar dapat menarik temanteman mereka untuk berkunjung ke tempat wisata yang dimaksud. Hal ini sekaligus juga untuk mempromosikan obyek wisata yang ada di Surabaya.

Beberapa remaja lain berpendapat bahwa magang, menjadi anggota komunitas pariwisata, memakai fasilitas, dan mengikuti berbagai kegiatan di obyek-obyek wisata juga merupakan salah satu cara mereka berpartisipasi dalam pariwisata di Surabaya.

Apakah Pariwisata memberikan keuntungan bagi remaja? Dari 20 orang responden, yang menjawab memberikan keuntungan sebanyak 16 orang, tiga orang menjawab tidak memberikan keuntungan, dan satu orang responden tidak menjawab. Keuntungan yang bisa didapat dari kegiatan pariwisata antara lain: untuk sarana hiburan sekaligus menghilangkan penat dan stress setelah beraktivitas, beberapa responden berpendapat kegiatan pariwisata selain untuk menambah wawasan pendidikan juga dapat dijadikan sarana mencari pekerjaan dan menambah income bagi masyarakat di sekitar obyek wisata.

\section{Educating Resident about Tourism}

Partisipasi masyarakat terhadap keberadaan obyek wisata yang ada di Surabaya merupakan hal yang cukup penting untuk 
menjaga keberlangsungan sebuah obyek wisata. Keterlibatan masyarakat dalam kegiatan pariwisata serta merta akan menumbuhkan kepedulian terhadap ha-hal yang berkaitan dengan pariwisata, salah satunya adalah mempromosikan pariwisata.

Berkaitan dengan cara ikut serta mempromosikan kepariwisataan Surabaya, mayoritas responden menjawab mempromosikan obyek-obyek wisata di Surabaya dapat dilakukan dengan berbagai cara salah satunya menggunakan media sosial seperti Facebook, Twitter, dan Instagram. Ketiga media sosial ini sering dimanfaatkan oleh responden dalam mempromosikan kepariwisataan di Surabaya. Ini merupakan salah satu cara dalam memasarkan obyek wisata yang bebas biaya.

\section{Simpulan}

Pengetahuan responden tentang obyekobyek wisata yang ada di Surabaya secara keseluruhan belum begitu baik. Hal ini nampak ketika responden diminta untuk menyebutkan secara lebih mendalam tentang keberadaan obyek-obyek wisata di Surabaya, selain nama, tempat atau lokasi obyek, harga tiket masuk hingga atraksi wisata yang dapat dinikmati di sana. Mayoritas reponden hanya tahu nama obyek-obyek wisata yang banyak dikunjungi oleh wistawan, antara lain Kebun Binatang Surabaya, Taman Hiburan Rakyat Surabaya, Monumen Kapal Selam, House of Sampoerna, Tugu Pahlawan, dan Wisata Mangrove.

Dengan frekwensi kunjungan yang ratarata hanya sekali menyebabkan responden tidak terlalu paham dengan keberadaan obyek-obyek dimaksud, seperti tiket masuk, dan atraksi wisata yang dapat dinikmati. Dari hasil wawancara responden secara keseluruhan tentang kondisi pariwisata di Surabaya diketahui bahwa masih banyak hal yang harus diperhatikan dan dibenahi oleh pemerintah kota Surabaya secara umum dan pengelola obyek wisata secara khusus. Seperti masalah kebersihan obyek wisata, keamanan, tempat parker, dan fasilitasfasilitas yang dapat dimanfaatkan oleh para remaja seperti wifi, dan tempat untuk olah raga.

Dari hasil penelitian didapatkan fakta bahwa partisipasi remaja lokal dalam pariwisata di Surabaya masih sangat minim, terutama dalam hal keterlibatan dalam pengambilan keputusan berkaitan dengan pariwisata. Keterlibatan remaja dalam pariwisata diharapkan dapat menimbulkan inovasi-inovasi baru di bidang pariwisata, karena remaja identik dengan semangat dan ide-ide baru.

\section{Saran}

Keberadaan obyek-obyek wisata di kota Surabaya merupakan salah satu daya tarik yang harus tetap dipertahankan. Oleh karena itu, untuk dapat menarik lebih banyak wisatawan baik lokal maupun manca negara untuk berkunjung di kota Surabaya perlu pengelolaam yang lebih baik terhadap obyek-obyek wisata yang ada, mulai masalah kebersihan, keamanan, dan melengkapi fasilitas yang dibutuhkan oleh konsumen. Sehingga ke depan jika obyek-obyek wisata yang ada sudah lebih baik dari sekarang, diharapkan masyarakat Surabaya tidak lagi ke luar kota untuk melakukan kegiatan wisata. 


\section{Daftar Pustaka}

Ap, J. 1992. Residents' perceptions on tourism impacts. Annals of Tourism Research, 19(4), 665-690.

Aref, F., \& Ma'rof, R. 2008. Barriers to community participation toward tourism development in Shiraz, Iran. Pakistan Journal of Social Sciences, 5(9), 936-940.

Choi, H. C., \& Sirakaya, E. 2005. Measuring residents' attitude toward sustainable tourism: Development of sustainable tourism attitude scale. Journal of Travel Research, 43(4), 380-394

Choi, H. C., \& Sirakaya, E. 2006. Sustainability indicators for managing community tourism. Tourism Management, 27(6), 1274-1289.

Cornelissen, S. 2005. The global tourism system: Governance, development and lesson from South Africa - new directions in tourism analysis. England: England: Ashgate Publishing Limited.

Cole, S. 2008. Tourism, culture and development: Hopes, dreams and realities in East Indonesia. Clevedon, UK: Channel View Publications.

Grybovych, O., Hafermann, D., \& Mazzoni, F. 2011. Tourism planning, community engagement and policy innovation in Ucluelet, British Columbia. In D. Dredge \& J. Jenkins (Eds.), Stories of practice: Tourism policy and planning (pp. 79-103). Surrey, England: Ashgate Publishing Limited.

Hall, C. M. 1995. Introduction to tourism in Australia: Impacts, planning and development. London: Longman.

Hall, C. M. 2008. Tourism planning: Policies, processes and relationships (2nd ed.). Essex, England: Pearson Educated Limited.

Harrison, D. 1992. International tourism and less developed countries: The background In D. Harrison (Ed.), Tourism and the less developed countries. England: John Wiley and Sons Ltd.

Lamberti, L., Noci, G., Guo, J., \&Zhu, S. 2011. Mega-events as drivers of community participation in developing countries: The case of Shanghai world expo. Tourism Management, $32(6), 1474-1483$.

Li, W. 2006. Community decision making participation in development. Annals of Tourism Research, 33(1), 132-143.

Liu, A., \& Wall, G. 2006. Planning tourism employment: A developing country perspective. Tourism Management, 27(1), 159-170.

Roberts, S. 2013. An exploratory analysis of factors mediating community participation outcomes in tourism. In R. Phillips \& S. Roberts (Eds.), Tourism, planning, and community development (pp. 35-49). Oxon: Routledge.

Rossman, G. B., \& Rallis, S. F. 2003. Learning in the field: An introduction to qualitative research. Thousand Oaks: Sage.

Saxena, N. C. 2011. What is meant by people's participation. In A. Cornwall (Ed.), The participation reader (pp. 31-33). New York: Zed Books Ltd.

Telfer, D. J., \& Sharpley, R. 2008. Tourism and development in the developing world. Oxon: Routledge. 
Timothy, D. J. 1999. Participatory planning: A view of tourism in Indonesia. Annals of Tourism Research, 26(2), 371-391.

Timothy, D. J. 2002. Tourism and community development issues. In R. Sharpley \& D. J.Telfer (Eds.), Tourism and Development: Concept and Issues (pp. 149-164). Clevedon, UK: Channel View Publications.

World Travel and Tourism Council. 2012. The review 2011. Retrieved 6 November, 2012, from http://www.wttc.org/site_media/uploads/downloads/WTTC_Review_2011. pdf

Zhang, J., Inbakaran, R. J., \& Jackson, M. 2006. Understanding community attitudes toward tourism and host-guest interaction in the urban-rural border region. Tourism Geographies, 8(2), 182-204. 
